\title{
Management of arrhythmia in sepsis and septic shock
}

\author{
Martin Balik, Vojtech Matousek, Michal Maly, Tomas Brozek \\ Department of Anaesthesiology and Intensive Care, $1^{\text {st }}$ Faculty of Medicine, Charles University \\ and General University Hospital in Prague, Czechia
}

\begin{abstract}
The occurrence of supraventricular arrhythmias is associated with an unfavourable prognosis in septic shock. Available trials are difficult to apply in sepsis and septic shock patients due to included cohorts, control groups and because "one size does not fit all". The priorities in the critically ill are maintenance of the sinus rhythm and diastolic ventricular filling. The rate control modality should be reserved for chronic AF and in situations when the sinus rhythm is difficult to maintain due to extreme stress conditions resulting from a high dosage of vasoactive agents. Electric cardioversion is indicated in unstable patients with an absence of contraindications and is more feasible in combination with an antiarrhythmic agent. Besides amiodarone being preferred for its lower cardiodepressant side effect compared to other agents, drugs with a different degree of betablocking activity are very useful in supraventricular arrhythmias and septic shock, providing echocardiography is routinely used to support their indications within the current summary of product characteristics. A typical patient benefiting from propafenone is without significant structural heart disease, i.e. typically with normal to moderately reduced left ventricular systolic function. Future research should be channelled towards echocardiography-guided prospective controlled trials on antiarrhythmic therapy which may clarify the issue of rhythm versus rate control, the effects of various antiarrhythmic drugs, and a place for electric cardioversion in critically ill patients in septic shock.
\end{abstract}

Anaesthesiology Intensive Therapy 2017, vol. 49, no 5, 419-429

Key words: septic shock, supraventricular arrhythmia, atrial fibrillation, propafenone, amiodarone, metoprolol, esmolol, betablockers, electric cardioversion

\section{SEPSIS AND SEPTIC SHOCK ASSOCIATED ARRHYTHMIAS}

Septic shock is characterized by a reduced afterload, unstable filling conditions, LV diastolic and systolic dysfunction, catecholamine surge and chronotropic dysregulation, all of which together may lead to rhythm disorders [1-7]. The impact of sepsis-related fever on the heart rate (HR) is also a contributing factor.

An important manifestation of sepsis is autonomic dysfunction with a low HR variability [8] and an inadequately high HR [9]. An inadequately high HR has been shown to downregulate catecholamine receptors [10] and thus may attenuate one's response to catecholamine treatment. Moreover, an inadequately high HR may further potentiate myocardial impairment, lead to arrhythmias and worsen diastolic function and filling $[11,12]$ with a subsequent decrease in stroke volume. More than $50 \%$ of patients with heart failure in the ICU display diastolic heart failure, often associating with a rhythm disorder [13].

Amongst the general ICU population, the incidence of SV arrhythmias is increased in septic shock patients, and is associated with worse short and long-term prognoses [14-16].

The most common arrhythmia is a new-onset atrial fibrillation (NOAF) [17], which represents up to $70 \%$ of all SV arrhythmias in septic shock [18]. Besides NOAF, $14.5 \%$ of patients present with chronic AF [18]. NOAF is associated with a prolonged ICU length of stay and a higher SOFA score, while failure to restore a sinus rhythm is associated with increased mortality [18-20]. A typical time to arrhythmia onset is within the first $72 \mathrm{~h}$ from the onset of septic shock [5, 18, $19,21]$. The overall cardioversion rate has been reported as between $70 \%$ and $87 \%$, including all those with additional electric cardioversion [18, 19, 21]. 


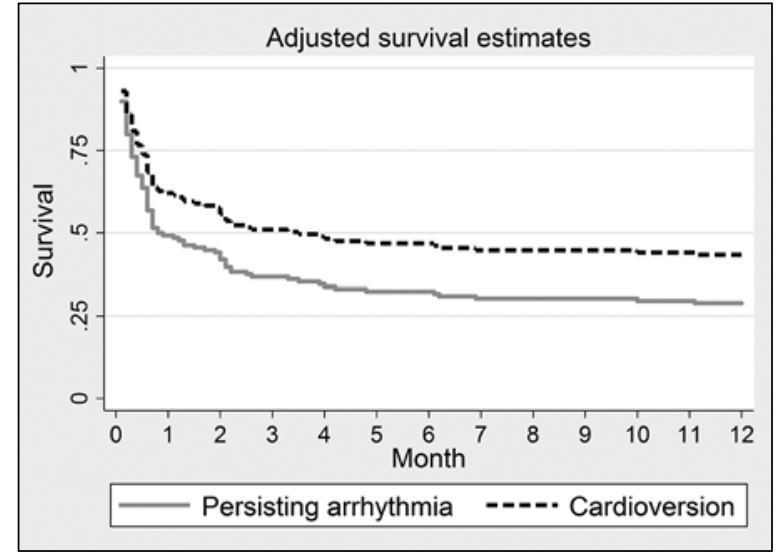

Figure 1. Multivariate analysis showing insignificant 12-month benefit in cardioverting septic shock patients to sinus rhythm (HR $0.67, P=0.113)$. Data from [18]

The reported ICU mortality of patients in septic shock responding to antiarrhythmic therapy was $33.5 \%$, while the 28 day mortality was $43.6 \%$. These were not significantly different to chronic AF patients with an ICU mortality of $38.2 \%$ and a 28-day mortality of $41.1 \%$ [18]. Despite treatment, according to available data, some $30-35 \%$ of patients $[5,14,18,19]$ remain in NOAF. Their ICU and 28-day mortalities were between $45 \%$ and $56 \%$, respectively which in the available studies did not reach statistical significance when compared to cardioverted patients $[18,19]$. In a recent study [18], the univariate analysis (excluding chronic AF patients) showed a one-year mortality benefit in favour of restoration of SR in septic shock (HR 0.48, $P=0.002$ ). However, when adjusting for age, dosage of noradrenaline, SOFA score and presence of CRRT, the statistical significance was not confirmed (HR 0.67, $P=0.113$, Fig. 1).

\section{ARRHYTHMIAS IN SEPTIC STATES - CAUSATIVE FACTORS}

Causative factors for arrhythmias in a septic patient may also be revealed in the medical history, particularly in previous heart disease and medication. Beta-blockers may affect the incidence of rhythm disturbances by betablocker withdrawal [22]. In a recent paper on SV arrhythmias in septic shock patients with high illness severity, antiarrhythmic drugs were taken prior to the admission to the ICU in $58 \%$ of patients [18]: $18.8 \%$ had received betablockers, $8.1 \%$ amiodarone, $1.3 \%$ amiodarone and betablockers, $4.7 \%$ propafenone and $2.6 \%$ digoxine.

Similarly, genetic predispositions or subclinical ischemic heart disease may manifest themselves under circumstances of elevated stress and metabolic demand.

The appearance of arrhythmias may also relate to pathogenic factors. Exotoxins like streptolysin $\mathrm{O}$ [23] or pneumo- lysin with cardiotoxic potential cause septic cardiomyopathy leading to arrhythmias [24]. In pneumoccal infections, platelet-activating factor receptor activation by the bacterial cell wall plays the same role [25]. Endotoxins like lipopolysaccharide of Gram-negative bacteria may contribute to the onset of arrhythmia, probably by its Toll-like receptor mediated action [26]. SIRS cause increased metabolic demand and intracellular derangement, including mitochondrial dysfunction. The effects of inflammatory mediators also promote cardiac arrhythmias.

\section{FLUID THERAPY VS. DIASTOLIC DYSFUNCTION}

In septic patients, associated diastolic dysfunction is very frequent (up to $61.8 \%$ [27]). In contrast with systolic dysfunction, diastolic dysfunction is an independent mortality predictor [28]. There is an emerging risk of excessive fluid resuscitation and worsening of tissue oedema and hypoperfusion [29] or vice versa, inadequate volume expansion in patients with pre-existing severe diastolic dysfunction [27].

Recent meta-analyses provide a new perspective on Early Goal Directed Therapy (EGDT), which in the setting of contemporary developed intensive care, shows minimal [30] or no [31-33] benefit, yet brings a potential risk of fluid overload during the initial aggressive volume resuscitation, reaching $67 \%$ on the first day [34]. Moreover, the widespread application of EGDT after 2001 led to a surge in betastimulation aimed at achieving sufficient central venous blood saturation. The available studies show increased rates of dobutamine and dopexamine administration [35] in septic shock patients with no morbidity and mortality benefit [32]. As a matter of fact, achieving a saturation rate above $65-70 \%$ may be associated with an unnecessaryily high cardiac output and $\mathrm{DO}_{2}$, recalling Shoemaker's concept of supramaximal oxygen delivery. This, together with advocated static measures of preload [36], may expose patients to a potentially arrhythmogenic setting. Static parameters such as CVP (above $8 \mathrm{~mm} \mathrm{Hg}$ ) and PAWP (above $12 \mathrm{~mm} \mathrm{Hg}$ ) may predict adequate preload in some $54 \%$ of septic shock patients [37], calling for other functional and dynamic parameters of preload. The administration of betastimulation in poorly controlled preload causes tachycardia, shortens diastolic filling times and leads to falsely elevated static parameters in a hypovolaemic patient. In the context of low afterload, this may also lead to left ventricular outflow tract obstruction which is, in the context of EGDT, reported in high rates (22\% [38]). Not surprisingly, ceasing betastimulation as part of EGDT and the administration of low-dose betablockers with the correction of preload has led to a dramatic decrease in mortality [39].

The administration of catecholamine to correct low vascular resistance in septic shock is proarrythmogenic in 
relation to rather parallel than previous preload correction, as well as to the targeted perfusion pressure [40]. Although, it is recommended to initiate vasopressors in septic shock with profound hypotension early [41], this should not be done without adequate parallel preload assessment [42]. The timely administration of vasopressin to reduce a high dosage of vasopressors may taper the predisposition to arrhythmias in septic shock [43].

Therefore, meticulous and repeated echocardiographic assessment of both the cardiac function and the intravascular volume status seems to be the logical approach, keeping in mind that suboptimal volume replacement leads to higher sympathetic tone and thus greater endogenous adrenergic stimulation, along with an elevated need for exogenous catecholamines.

Both conditions, namely fluid overload and hypovolaemia, are triggering factors for developing arrhythmias. Even though the relation of diastolic dysfunction and atrial fibrillation in the non-criticallyill population is well documented [44], studies for critically ill or septic patients are needed.

\section{POTENTIAL IMPACT OF MECHANICAL VENTILATION}

The effects of mechanical ventilation should not be omitted either. Aggressive modalities and attempts to recruit consolidated lungs without parallel haemodynamic check ups to exclude right ventricular dysfunction may critically increase right ventricular afterload causing acute cor pulmonale and SV arrhythmias [45-47]. Gradual and slow opening of the consolidated inflammatory lungs, ideally in a prone position and with the aid of bedside chest ultrasound and echocardiography, may prevent SV arrhythmias and the aggravation of haemodynamic instability [48] due to IPPV in a patient with severe respiratory failure.

\section{MEDICATION}

Besides exogenous catecholamines, antimicrobial agents may increase the risk of arrhythmia in sepsis. QTC prolongation leads to a risk of ventricular arrhythmias, especially torsades de pointes, after the administration of macrolides, fluoroquinolones, halofantrine (antimalarial), pentamidine, azole antifungals $[49,50]$, as well as with the combination of ceftriaxone and lansoprazole [51] or with antiretroviral drugs [52]. QTc altered after trimethroprim-sulfamethoxazole may be rare [53]. Two studies on non-septic patients $[54,55]$ showed no difference in the incidence of arrhythmia between different groups of macrolides, indicating that illness severity is probably the most important factor. A recent meta-analysis found no significant potential for provoking arrhythmias in macrolides [56]. Ivabradine by its $I_{f}$ (funny current) channel-blocking action slows the sinoatrial node and decreases the heart rate without un- wanted compromise of contractility. It should be noted that ivabradine, as a chronic medication, may potentiate the risk of developing NOAF (15\% increase in the relative risk) [57]. Its use in critical care is extremely limited by its oral form and poor evidence, although a case series showed a benefit in catecholamine-induced tachycardia [58] and sepsis in cardiosurgical patients [59].

\section{ELECTROLYTE DISTURBANCES IN SEPSIS}

Hypophosphatemia is more frequent in the critically ill than in the general population and, besides other negative consequences, is associated with decreased myocardial contractility and a higher incidence of ventricular arrhythmias [60]. A small case series showed that phosphorus supplementation may be beneficial in preventing new-onset arrhythmias in a septic patient [61].

Up to $61 \%$ of critically ill patients present with low magnesium levels at ICU admission. Hypomagnesaemia is common in septic patients and is associated with poor outcomes [62]. Both supra- and ventricular arrhythmias are one of the various manifestations of hypomagnesaemia. While the routine supplementation of magnesium is recommended for the general ICU population [63], specific data for arrhythmias in sepsis are not available.

Similarly, hypocalcaemia may be associated with arrhythmias [64]. Although the prolonged QTc interval and ventricular arrhythmias may be provoked by a chronically decreased level of ionized calcium, no studies for sepsis are available [65].

Dyskalaemias are the most known ion abnormalities with arrhythmogenic potential but are not encountered exclusively in sepsis. Potassium levels are closely related with $\mathrm{pH}$ and should not be perceived and corrected separately from disturbances of acid-base status.

Hypokalaemia is not uncommonly caused by medication. Hypocalcaemia and hypomagnesaemia should be corrected if the potassium level does not respond to adequate supplementation [64]. Besides medication-related factors, hyperkalaemia may be caused by renal failure in septic patients with inadequate fluid management. Its treatment depends on the severity of symptoms.

\section{ANTIARRHYTHMIC THERAPY}

The priorities in therapy of arrhythmias in sepsis and septic shock are to prevent diastolic heart failure, posttachycardic systolic heart failure and dilatation. This goes hand in hand with the maintenance of stroke volume, cardiac output and myocardial $\mathrm{DO}_{2} / \mathrm{VO}_{2}$. Persistent arrhythmia may potentiate microthrombi formation within the heart, in relation to systolic function, the size of atria, ventricles and valvular disease. This issue has not been fully clarified in the critically ill yet. Minute silent brain infarctions related 
to cognitive dysfunction have been reported on NMR, even in fully anticoagulated patients with chronic AF while sepsis is often a procoagulant state, with septic encephalopathy of a multifactorial etiology $[66,67]$.

Besides improving oxygenation, preload and electrolyte corrections, the mainstay of treatment is represented by amiodarone, preferred for its lower cardiodepressant side effects compared to other agents and electric cardioversion $[15,16,68,69]$.

A haemodynamically unstable patient with new onset SV arrhythmia may require immediate electric cardioversion to secure cardiac output and perfusion pressure. The role of electric cardioversion has not been studied in sepsis-related arrhythmias. In cardiosurgical ICU patients, the biphasic modality was immediately successful in restoring a sinus rhythm in $71 \%$ of sessions with high rates of early relapse of atrial fibrillation [70]. Its effect may be improved by concomitant antiarrhythmic medication. When electrically cardioverting $24 \%$ of septic shock patients on amiodarone and $36 \%$ on propafenone, the overall rate of sinus rhythm maintenance was significant (74\% and 89\%, respectively) [18].

Antiarrhythmic agents are administered in SV arrhythmia, compromising circulation in patients already on an infusion of NAD for septic shock. Ideally, complex haemodynamic monitoring, including echocardiography, is also applied to correct preload and to avoid administering a betablocker or propafenon in severe LV systolic dysfunction.

\section{AMIODARONE}

Amiodarone is a class III antiarrhythmic drug, one most widely used in intensive care with the potential to treat both atrial and ventricular arrhythmias. With its long half life, it is eliminated by hepatic metabolism and not by dialysis [71, 72].

In a recent study on septic shock and SV arrhythmias [18], amiodarone was the primary drug of choice in $76 \%$ of patients, which was likely due to the haemodynamic instability of patients in septic shock on vasoactive agents. Restoration to SR was achieved in $74 \%$ patients while $23.7 \%$ of them required additional electric cardioversion. Nevertheless, $26 \%$ of patients failing to restore SR were converted to propafenone during the first $24 \mathrm{~h}$, which increased overall rhythm control to $86 \%$ under propafenone. The median total dose of amiodarone was 3.0 (1.8-4.6) g, given by infusion over 4 (2-6) days with a median of $1.4(0.9-1.8) \mathrm{g}$ during the first day [18].

Amiodarone carries potentially significant side effects while the evidence of its efficacy in the septic shock population is lacking $[14,15,73]$. This is in contrast to its widespread use.

Amiodarone and its metabolites are not stable in aqueous solutions and therefore must be dissolved in a solvent which contains a mixture of diluent polysorbate and ben- zylalcohol which are related to many adverse effects, particularly due to their lipid solubility.

Its adverse effects involve many organ systems and result in cessation of the medication in $10 \%$ to $15 \%$ of patients. Amiodarone contains iodine and interferes with thyroid function. Thyroid dysfunction has wide range from hypothyroidism [74] to triggering of hyperthyroid crisis with lengthy consequences [75].

Hypotension due to vasodilatation, and particularly QTC prolongation, have been observed. This may trigger the occurrence of torsades-des-pointes type of ventricular tachycardia. The side effect can be potentiated by concomitant drugs like antihistamines, antimalarials, antipsychotics, lithium, tricyclic antidepressants, antimycotics, or some antimicrobials [71, 72].

Other important side effects include corneal microdeposits, hepatic dysfunction (1-2\% in intravenous use) $[76,77]$, pulmonary fibrosis (in 5-10\%), slowly progressive interstitial pneumonia with bilateral diffuse infiltrates [78, 79], skin discoloration and neuropathies [71, 72].

\section{PROPAFENONE}

The use of $1 \mathrm{C}$ class antiarrhythmic drugs in SV arrhythmia treatment has not been properly evaluated in the critically ill. There are only a few case reports describing serious adverse effects apparently related to their dose-related cardiotoxicity [80-82]. Moreover, their usage has been discouraged by reports describing cardiotoxicity and poor outcomes on long-term use in the cardiology population [80]. Consequently, $1 \mathrm{C}$ class agents, like propafenon and flecainide [83], are not routinely used in the critically ill, regardless of the limited application of these conclusions for fully monitored intensive care patients. Propafenon is derived from propandiolamine, which is a chemical compound of betablockers, and acts on the rapid depolarizing phase (phase 0 ) and also, to minimal extent, on beta-adrenergic receptors $[73,84]$.

A recent study [18] suggests that propafenon could be a drug of choice in septic shock patients with normal to moderately reduced EF-LV. In addition, the benefits of propafenon have been proved in patients where amiodarone is not capable of maintaining the SR. The routine dosage might be capable of restoring SR without an adverse effect on haemodynamics and with a possible benefit on the outcome (Figs 2, 3). Propafenon was used as a primary antiarryhthmic in septic shock in $17.5 \%$ of patients. The pool of patients on propafenone rose to $33 \%$ after administering the agent in patients who were not able to cardiovert and maintain a sinus rhythm on amiodarone [18]. There was an overall cardioversion success rate of $86.1 \%$ at $24 \mathrm{~h}$, while $35.5 \%$ needed additional electric cardioversion to achieve SR. The chance of cardioverting seems to be significantly 


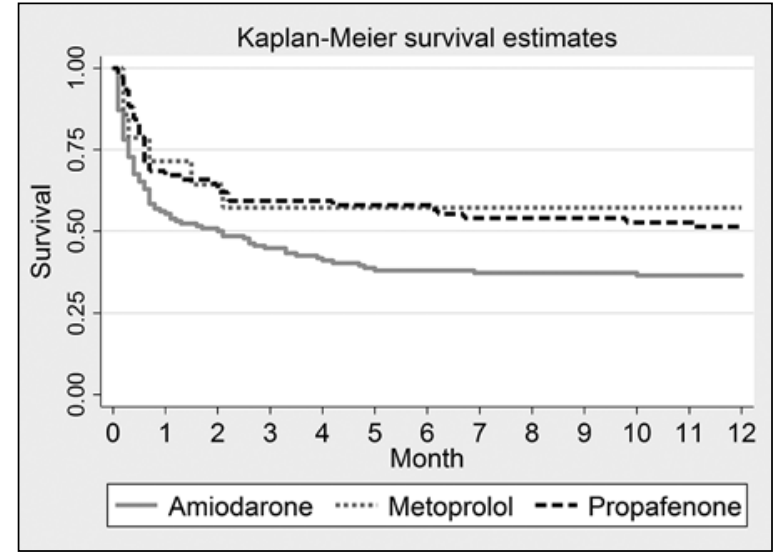

Figure 2. Univariate analysis showing long-term survival of those with propafenone-treated SV arrhythmias similar to those treated with metoprolol and higher than in amiodarone-treated patients (HR $1.76[1.06 ; 2.3], P=0.024)$. Data from [18]

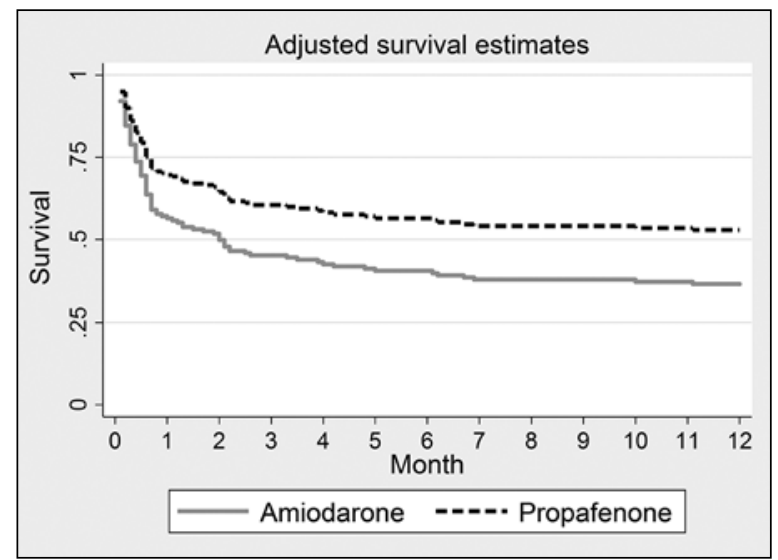

Figure 3. Multivariate analysis showing adjusted 12-month survival benefit in favour of propafenone vs. amiodarone (HR $1.58(1.04 ; 2.4)$, $P=0.03)$. Data from [18]

higher under propafenon than in amiodarone and is almost the same as under the betablocker, metoprolol (93\%).

The median propafenon dosage was $2.5(1.0-4.0) \mathrm{g}$ while the duration of treatment was 5.0 (2.0-8.5) days. The median propafenon dose was 670 (460-700) mg/day. A 12-lead ECG was routinely taken every 12 hours on propafenone, while no ventricular arrhythmias or conduction disorders requiring treatment other than adjustment of the rate of infusion were observed [18].

Administering propafenone for SV arrhythmia in septic shock is associated with insignificantly lower ICU and 28-day mortalities compared to amiodarone. In contrast, a statistically significant 12-month mortality benefit in favour of propafenone was found (Figs 2,3). This result might be influenced by a baseline characteristic of the propafenone group not included in the multivariate analysis, one which needs to be clarified by a prospective study.
Although the higher mortality of the amiodarone group (Fig. 3) may be explained by its less efficient antiarrhythmic action, there were other major confounding factors. While being statistically not significant, the LV systolic function was higher in propafenone and betablocker patients compared to those on amiodarone. The dosage of NAD was significantly higher in the amiodarone group compared to the other two, likely reflecting the severity of septic shock. Nevertheless, compared to propafenon, the higher illness severity presumed in the amiodarone group was not found to be associated with any other available strong outcome predictor, such as rates of CRRT, procalcitonin, SOFA and APACHE II scores. Moreover, the dosage of NAD was not related to 12-month mortality in a multivariate regression analysis [18].

Drugs with a different degree of betablocking activity are very useful in SV arrhythmias while septic shock providing echocardiography is routinely used to support their indications within the current summary of product characteristics. A typical patient benefiting from propafenone is without significant structural heart disease, i.e. typically with normal or mildly reduced left ventricular systolic function.

\section{BETA-BLOCKERS}

Beta-blockers are a potential option in order to manage sepsis-related atrial fibrillation, both for prevention and treatment. A beta-blockade withdrawal syndrome is a risk factor for atrial fibrillation. Likewise, decisions regarding the administration of a betablocker should consider chronic beta-blockade status [22].

The discussion about the use and effect of betablockers in sepsis has lasted for decades. In contrast, we have faced an era of betastimulation since the 1980s which somehow culminated with the Surviving Sepsis Campaign [36] with a possible impact on myocardial function [29].

Autonomic dysfunction in septic shock may be accompanied by extreme tachycardia and high cardiac output. Protecting the heart under stress conditions requires one to reduce the unnecessary load of catecholamines and the stimulation of their receptors $[9,85]$. Studies show that using the easily titratable betablocker esmolol may be safe in those patients who require NAD in parallel for low SVR and hypotension.

The reported benefits of betablockers in sepsis and septic shock [86-90] could be related to the extension of diastolic filling time, improvement of LV diastolic function and arrhythmia management. The rates of septic cardiomyopathy [91] suggest an associated risk for arrhythmias. The administration of betablockers with concomitant vasopressors has been shown to have beneficial effects in animal models of septic shock and in cohorts of septic patients [92-96].

Although limiting systemic adrenergic activation may be beneficial, it may be also detrimental in improperly moni- 
tored patients with compromised heart function. Moreover, in HR below 100 per min, the infusion of a betablocker may result in a cardiac output inadequate to systemic oxygen demand in septic shock. The importance of at least including echocardiography combined with continuous monitoring, or with repeated echocardiographic exams, is evident.

The current studies on tachycardic patients with septic shock requiring catecholamine administration suggest the benefit of slowing HR by approximately $20 \%$ with intravenous administration of the titratable betablocker esmolol.

Mean esmolol infusion rates varied between $213 \pm 64$ $\mathrm{mg} \mathrm{h}^{-1}$ at the start to $273 \pm 90 \mathrm{mg} \mathrm{h}^{-1}$ at $24 \mathrm{hrs}$ and slowed the HR significantly down from $142 \pm 11$ per min to 112 \pm 9 per min $(P<0.001)$. MAP or SVR did not significantly change during the study and no significant increase in NAD infusion was required. Esmolol tended to increase stroke volume which resulted in no significant decrease in $\mathrm{CO}$ or $\mathrm{Cl}$ during esmolol administration. A continuous betablockade did not induce significant changes in $\mathrm{DO}_{2}$, $\mathrm{VO}_{2}$ or OER $[97,98]$. A similar impact on haemodynamics was reported by Morelli who used a very low dosage of $100 \mathrm{mg} \mathrm{h}^{-1}$ as part of the applied EGDT protocol with no echocardiography or verification of the absence of contraindications to a betablocker. Although in this setting, the dosage of NAD was reduced, $49.4 \%$ of patients received a rescue levosimendan infusion [39].

A new ultra-short beta-blocker with a half-life of only 4 minutes and a high beta- 1 selectivity is landiolol, and which has been used for the treatment and prevention of atrial fibrillation. Landiolol has also been shown to be well tolerated in the critically ill for its limited negative inotropic effect and minimal impact on blood pressure [99-101]. The use of low doses (5-10 $\mathrm{mcg} \mathrm{kg}^{-1} \mathrm{~min}^{-1}$ ) of landiolol is usually sufficient for the cardioversion of AF compared to controls. In sinus tachycardia, landiolol may prevent the occurrence of arrhythmias in a lower dose (3-5 $\left.\mathrm{mcg} \mathrm{kg}^{-1} \mathrm{~min}^{-1}\right)$ [99].

There was no report of bronchospasm when using titrated betablockers in patients with atrial fibrillation [102].

Metoprol is well tolerated in septic shock patients with an SV arrhythmia. In septic shock-related NOAF medicated with i.v. metoprolol, a sinus rhythm was achieved in 92.3\% patients with no additional electric cardioversion. The median length of treatment was 5 (2-9) days, while the median intravenous metoprolol dose was 84 (48-120) $\mathrm{mg} \mathrm{day}^{-1}[18]$.

Betablockers are the medication of choice for a wellselected cohort of septic shock patients $[88,89]$. In a recent paper, only $6 \%$ of septic shock patients with SV arrhythmias were medicated with betablockers [18]. An indication to use drugs other than amiodarone (betablockers, propafenone) may be also supported by the rates of thyroid disease $[73,75]$.

\section{DIGOXIN}

Digoxin has a dual mechanism of action, slowing cardiac conduction through the AV node and increasing the force of myocardial contraction (inhibiting the sodium-potassium pump, increasing the calcium availability to the contractile apparatus) [103]. Its indication in critically ill is represented, in particular, by atrial fibrillation with rapid ventricular response-rate control therapy. Although most studies include non-ICU patients, there is paucity of data regarding critically ill patients and patients in sepsis and septic shock. Digoxin may reduce the number of hospital admissions when given in combination with ACE inhibitors and diuretics in patients with an EF-LV lower than 45\%. Various other metanalyses and studies have suggested a relationship between digoxin therapy for atrial fibrillation and increased all-cause and cardiovascular mortality in cardiology outpatients [104, 105] or septic patients with low illness severity [106]. A recent metaanalysis showed zero impact on outcomes [107].

All these studies are hardly applicable to closely monitored critically ill patients due to their design, included cohorts of non-ICU patients and no attempt to select those who may benefit from rate control therapy. Digoxin's efficacy decreases with adrenergic stress, which may be limiting in the critically ill. On the other hand, its positive inotropic effect may be beneficial for the treatment of heart failure with left ventricular systolic dysfunction $[21,108]$.

Moreover, this drug may be very useful in a chronic atrial fibrillation with rapid ventricular response, even in critically ill septic shock patients. While the optimal dosage is between $0.75-1.5 \mathrm{mg}$, given in $0.125 \mathrm{mg}$ increments according to the optimal ventricular response, the onset of the full effect is usually delayed and the drug should be given with caution in renal insufficiency and in combination with other antiarrhythmic agents.

\section{DISCUSSION}

An important issue is the applied definition of sepsis and septic shock. A diagnosis of septic shock is usually made according to the criteria set for systemic inflammatory syndrome [109] with the administration of NAD due to hypotension non-responsive to the correction of preload. In addition, a positivity of at least one inflammatory marker of the monitored CRP and PCT is expected, together with the administration of antibiotics for an infectious source.

The available literature on SV arrhythmias in septic shock shows critically ill patients in septic shock with a high predicted mortality, an IPPV rate of $99 \%$ and high rates of CRRT (27-31\%) [18]. As of now, all authors have adhered to the septic shock criteria based on volume non-responsive SIRS with a need for a vasopressor and antibiotic therapy administered for an infectious source [109]. Applying the novel septic shock criteria of 2016 [110] may increase specificity at 
the cost of lacking the sensitivity to include even those who could potentially benefit from septic shock therapy [111]. In addition, certain studies show high inflammatory markers (e.g. PCT) suggesting a high rate of bacteraemia among patients categorized according to the older SIRS criteria. The SOFA score and a median arterial lactate level may serve as controls adjusting the studied population in the context of the novel septic shock criteria published in 2016 [110].

The ICU routine is influenced by up-to-date haemodynamic monitoring incorporating echocardiography. The combination of ECG and echocardiography allows to indicate antiarrhythmics with the exclusion of a more cardiodepressant medication (betablocker or propafenone) in severe LV dysfunction and also to correct preload when attempting to cardiovert to SR. A hypercontractile ventricle or dynamic LVOT obstruction may rather, after correction of preload, indicate betablocker therapy. Echocardiography also helps one to decide whether to cardiovert a patient with an unknown history of arrhythmia. A finding of a significantly dilated left atrium or valvular disorder may be associated with chronic AF. In the absence of echocardiography, ECG findings of a structural heart disease, such as low $R$ waves in precordial leads, profound ischaemic changes or atrioventricular blockade, would contraindicate propafenone or a betablocker. A known history of moderate or severe LV dysfunction would also exclude other antiarrhythmics than amiodarone.

The clinical applicability of data in the current literature shows some important limitations. Looking at SV arrhythmias in general, one should realize that most of the included patients had atrial fibrillation. Other SV arrhythmias, such as atrial flutter, may be easier to cardiovert electrically while, for example, re-entrant SV tachycardia might be cardioverted by vagal manoeuvres like carotid sinus massage. If searching according to the antiarrhythmic medications used, we again likely missed some patients with SV arrhythmias, e.g. flutter, who were cardioverted electrically and not given antiarrhythmics at all [18]. The application of an echocardiographic protocol before deciding on treatment is also a limitation. Some of the available studies completely lack any attempt to avoid potentially unsuitable medication in an unstable critically ill patient. For example, a large pool (36\%) of patients in sepsis was medicated with calcium channel blockers which can help with the rate control at the cost of reducing ventricular contractility and promotion of vasodilatation, which would be difficult to justify in a patient with left ventricular compromise or profound vasoplegia [106]. Beneficial effects, including the outcome improvement of beta-blockers, have been suggested in septic shock patients [86-89]. Nevertheless, the comparisons to control patients were fraught with high mortality in the control group while the haemodynamic monitoring did not include echocardiography [87]. Several limitations have to be considered including the absence of echocardiographic cardiac function evaluation and the exclusion of the valve and conduction disorders, prior to beta-blocker administration in septic shock patients $[88,90]$. The same limitations regarding the absence of echocardiographic screening of cardiac function and haemodynamics exist in all the case series on various antiarrhythmic agents in sepsis and septic shock patients. Along with poorly defined inclusion and exclusion criteria, this might lead to misleading results [80].

Moreover, some of the echocardiography studies comprise rapid bedside assessment in a form of FATE/RACE protocol [112]. Therefore, we have limited dataset on the exact size/volume of the left atrium, various degrees of diastolic function, valve disorders, right ventricular dysfunction and pulmonary hypertension. The reported rates of various degrees of diastolic dysfunction likely underestimate reality [13].

If losing a sinus rhythm transmits so profoundly to the outcome, why we do not have enough data showing that reverting back to sinus [20] improves mortality and morbidity? The answer lies in the absence of critical care trials and the limited applicability of major cardiology trials [113-115] in the intensive care setting. In the long term, the recurrence and side effects of antiarrhythmics have led to tendency to rather provide rate control than rhythm control therapy. Nevertheless, the overlap between rhythm and rate control may be significant as shown in a recent study on perioperative AF where the two modalities included the same antiarrhythmic agents and showed similar rates of electric cardioversion in $25 \%$ of the patients included [116]. The rate control approach and resignation to restore the atrial contribution to the ventricular filling contrast with data showing that the loss of atrial kick is associated with two to five times increased mortality [5, 14, 21]. Various degrees of deterioration of the diastolic function in septic shock patients are associated with the prognosis. A left ventricular relaxation disorder is more dependent on atrial filling, as well as a pseudonormal LV filling compared to a restrictive LV filling with a possibly dilated poorly contracting left atrium. In parallel, this classic stratification of diastolic dysfunction relates to patient's prognosis in septic shock (2). Again, the available trials (PRCT) included all degrees of diastolic dysfunction without any attempt to stratify the degree of dependence of the ventricular filling on the atrial systole. Moreover, with exemption of the AF-CHF trial [113], the authors included all patients without stratification of the LV systolic function, and related left atrial remodelling which relates to the ability to maintain a sinus rhythm $[117,118]$.

The median age in an adult ICU varies around 55-65 years with a significant prevalence of hypertension and ischaemic heart disease. This suggest a large proportion of patients with dependence on ventricular filling of atrial sys- 
tole, thus suggesting a potential benefit of rhythm control. The prevalence of NOAF and a broad spectrum of potentially reversible triggers in the critically ill offer a better opportunity for cardioversion and maintenance of a sinus rhythm in closely monitored patients than in cardiology outpatients.

\section{CONCLUSIONS AND FURTHER RESEARCH}

In conclusion, current data confirms the mortality impact of an acute onset SV arrhythmia in the critically ill, here in the context of septic shock $[14,15]$. Therefore, actively pursuing SR and cardioverting patients may contribute to the treatment of diastolic dysfunction with a positive impact on mortality. Available PRCTs are difficult to apply for NOAF in the sepsis and septic shock patients due to included cohorts, control groups and because "one size does not fit all." The rate control modality should be reserved to a chronic AF and in situations when a sinus rhythm is difficult to maintain due to extreme stress conditions due to a high dosage of vasoactive agents. The electric cardioversion (preferably biphasic) is indicated in unstable patients with an absence of contraindications and is more feasible in combination with an antiarrhythmic agent. Future research should be channelled towards echocardiography guided prospective controlled trials on antiarrhythmic therapy which may clarify the issue of rhythm versus rate control, the effects of various antiarrhythmic drugs and a place for electric cardioversion in critically ill patients in septic shock.

\section{ACKNOWLEDGEMENTS}

1. This research has been supported in part from project reg.no. CZ.2.16/3.1.00/21565 from OP Prague Competitiveness. The sponsor did not have any role in the interpretation of the data, in the writing of the paper and in the decision to submit the article for publication.

2. Conflict of interest: none.

\section{References:}

1. Etchecopar-Chevreuil C, François B, Clavel M, et al. Cardiac morphological and functional changes during early septic shock: a transesophageal echocardiographic study. Intensive Care Med. 2008; 34(2): 250-256, doi: 10.1007/s00134-007-0929-z, indexed in Pubmed: 18004543.

2. Poelaert J, Declerck C, Vogelaers D, et al. Left ventricular systolic and diastolic function in septic shock. Intensive Care Med. 1997; 23(5): 553-560, indexed in Pubmed: 9201528.

3. Rudiger A, Singer M. Mechanisms of sepsis-induced cardiac dysfunction. Crit Care Med. 2007; 35(6): 1599-1608, doi: 10.1097/01. CCM.0000266683.64081.02, indexed in Pubmed: 17452940.

4. Bouhemad B, Nicolas-Robin A, Arbelot C, et al. Isolated and reversible impairment of ventricular relaxation in patients with septic shock. Crit Care Med. 2008; 36(3): 766-774, doi: 10.1097/CCM.0B013E31816596BC, indexed in Pubmed: 18431265.

5. Klein Klouwenberg PMC, Frencken JF, Kuipers S, et al. MARS Consortium *. Incidence, predictors, and outcomes of new-onset atrial fibrillation in critically ill patients with sepsis. A cohort study. Am J Respir Crit Care Med. 2017; 195(2): 205-211, doi: 10.1164/rccm.201603-06180C, indexed in Pubmed: 27467907.

6. Annane D, Trabold F, Sharshar T, et al. Inappropriate sympathetic activation at onset of septic shock: a spectral analysis approach.
Am J Respir Crit Care Med. 1999; 160(2): 458-465, doi: 10.1164/ ajrccm.160.2.9810073, indexed in Pubmed: 10430714.

7. Zorn-Pauly K, Pelzmann B, Lang $P$, et al. Endotoxin impairs the human pacemaker current If. Shock. 2007; 28(6): 655-661, indexed in Pubmed: 18092381.

8. Schmidt HB, Werdan K, Müller-Werdan U. Autonomic dysfunction in the ICU patient. Curr Opin Crit Care. 2001; 7(5): 314-322, indexed in Pubmed: 11805528.

9. Annane D, Trabold F, Sharshar T, et al. Inappropriate sympathetic activation at onset of septic shock: a spectral analysis approach. Am J Respir Crit Care Med. 1999; 160(2): 458-465, doi: 10.1164/ ajrccm.160.2.9810073, indexed in Pubmed: 10430714.

10. Cariou A, Pinsky MR, Monchi M, et al. Is myocardial adrenergic responsiveness depressed in human septic shock? Intensive Care Med. 2008; 34(5): 917-922, doi: 10.1007/s00134-008-1022-y, indexed in Pubmed: 18259725.

11. Chung CS, Kovács SJ. Consequences of increasing heart rate on deceleration time, the velocity-time integral, and E/A. Am J Cardiol. 2006; 97(1): 130-136, doi: 10.1016/j.amjcard.2005.07.116, indexed in Pubmed: 16377298.

12. Rudiger A, Singer M. Mechanisms of sepsis-induced cardiac dysfunction. Crit Care Med. 2007; 35(6): 1599-1608, doi: 10.1097/01. CCM.0000266683.64081.02, indexed in Pubmed: 17452940.

13. Saleh $M$, Vieillard-Baron $A$. On the role of left ventricular diastolic function in the critically ill patient. Intensive Care Med. 2012; 38(2): 189-191, doi: 10.1007/s00134-011-2448-1, indexed in Pubmed: 22212687.

14. Kuipers S, Klein Klouwenberg PMC, Cremer OL. Incidence, risk factors and outcomes of new-onset atrial fibrillation in patients with sepsis: a systematic review. Crit Care. 2014; 18(6): 688, doi: 10.1186/s13054014-0688-5, indexed in Pubmed: 25498795.

15. Arrigo $M$, Bettex $D$, Rudiger $A$. Management of atrial fibrillation in critically ill patients. Crit Care Res Pract. 2014; 2014: 840615, doi: 10.1155/2014/840615, indexed in Pubmed: 24527212.

16. Sleeswijk ME, Van NoordT, Tulleken JE, et al. Clinical review: treatment of new-onset atrial fibrillation in medical intensive care patients--a clinical framework. Crit Care. 2007; 11(6): 233, doi: 10.1186/cc6136, indexed in Pubmed: 18036267.

17. Koyfman L, Brotfain E, Kutz R, et al. Epidemiology of new-onset paroxysmal atrial fibrillation in the General Intensive Care Unit population and after discharge from ICU. A retrospective epidemiological study. Anaesthesiol Intensive Ther. 2015; 47(4): 309-314, doi: 10.5603/AIT. a2015.0040, indexed in Pubmed: 26210522.

18. Balik M, Kolnikova I, Maly M, et al. Propafenone for supraventricular arrhythmias in septic shock-Comparison to amiodarone and metoprolol. J Crit Care. 2017; 41: 16-23, doi: 10.1016/j.jcrc.2017.04.027, indexed in Pubmed: 28463737.

19. Meierhenrich R, Steinhilber E, Eggermann C, et al. Incidence and prognostic impact of new-onset atrial fibrillation in patients with septic shock: a prospective observational study. Crit Care. 2010; 14(3): R108, doi: 10.1186/cc9057, indexed in Pubmed: 20537138.

20. Liu WC, Lin WYu, Lin CS, et al. Prognostic impact of restored sinus rhythm in patients with sepsis and new-onset atrial fibrillation. Crit Care. 2016; 20(1): 373, doi: 10.1186/s13054-016-1548-2, indexed in Pubmed: 27855722.

21. Arrigo $M$, Bettex $D$, Rudiger $A$, et al. Management of atrial fibrillation in critically ill patients. Crit Care Res Pract. 2014; 2014: 840615, doi: 10.1155/2014/840615, indexed in Pubmed: 24527212.

22. Macchia A, Romero M, Comignani PD, et al. Previous prescription of $\beta$-blockers is associated with reduced mortality among patients hospitalized in intensive care units for sepsis. Crit Care Med. 2012; 40(10): 2768-2772, doi: 10.1097/CCM.0b013e31825b9509, indexed in Pubmed: 22824934.

23. Bolz DD, Li Z, Mclndoo ER, et al. Cardiac myocyte dysfunction induced by streptolysin $\mathrm{O}$ is membrane pore and calcium dependent. Shock. 2015; 43(2): 178-184, doi: 10.1097/SHK.0000000000000266, indexed in Pubmed: 25243426.

24. Sato R, Nasu M. A review of sepsis-induced cardiomyopathy. J Intensive Care. 2015; 3: 48, doi: 10.1186/s40560-015-0112-5, indexed in Pubmed: 26566443.

25. Brown AO, Millett ERC, Quint JK, et al. Cardiotoxicity during invasive pneumococcal disease. Am J Respir Crit Care Med. 2015; 191(7): 739745, doi: 10.1164/rccm.201411-1951PP, indexed in Pubmed: 25629643.

26. Monnerat-Cahli G, Alonso H, Gallego M, et al. Toll-like receptor 4 activation promotes cardiac arrhythmias by decreasing the transient outward 
potassium current (Ito) through an IRF3-dependent and MyD88-independent pathway. J Mol Cell Cardiol. 2014; 76: 116-125, doi: 10.1016/j. yjmcc.2014.08.012, indexed in Pubmed: 25169970.

27. Brown SM, Pittman JE, Hirshberg EL, et al. Diastolic dysfunction and mortality in early severe sepsis and septic shock: a prospective, observational echocardiography study. Crit Ultrasound J. 2012; 4(1): 8, doi: 10.1186/2036-7902-4-8, indexed in Pubmed: 22870900.

28. Sanfilippo F, Corredor C, Fletcher N, et al. Diastolic dysfunction and mortality in septic patients: a systematic review and meta-analysis. Intensive Care Med. 2015; 41(6): 1004-1013, doi: 10.1007/s00134-0153748-7, indexed in Pubmed: 25800584.

29. Landesberg G, Levin PD, Gilon D, et al. Diastolic dysfunction and mortality in severe sepsis and septic shock. Eur Heart J. 2012; 33(7): 895-903, doi: 10.1093/eurheartj/ehr351, indexed in Pubmed: 21911341.

30. Xu JY, Chen QH, Liu SQ, et al. The effect of early goal-directed therapy on outcome in adult severe sepsis and septic shock patients: a meta-analysis of randomized clinical trials. Anesth Analg. 2016; 123(2): 371-381, doi: 10.1213/ANE.0000000000001278, indexed in Pubmed: 27049857.

31. Jiang Lb, Zhang M, Jiang Sy, et al. Early goal-directed resuscitation for patients with severe sepsis and septic shock: a meta-analysis and trial sequential analysis. Scand J Trauma Resusc Emerg Med. 2016; 24: 23, doi: 10.1186/s13049-016-0214-7, indexed in Pubmed: 26946514.

32. Peake SL, Delaney A, Bailey M, et al. ARISE Investigators, ANZICS clinical trials group. goal-directed resuscitation for patients with early septic shock. N Engl J Med. 2014; 371(16): 1496-1506, doi: 10.1056/ NEJMoa1404380, indexed in Pubmed: 25272316.

33. Rowan KM, Angus DC, Bailey M, et al. PRISM Investigators. Early, goal-directed therapy for septic shock - a patient-level meta-analysis. N Engl J Med. 2017; 376(23): 2223-2234, doi: 10.1056/NEJMoa1701380, indexed in Pubmed: 28320242.

34. Kelm DJ, Perrin JT, Cartin-Ceba R, et al. Fluid overload in patients with severe sepsis and septic shock treated with early goal-directed therapy is associated with increased acute need for fluid-related medical interventions and hospital death. Shock. 2015; 43(1): 68-73, doi: 10.1097/ SHK.0000000000000268, indexed in Pubmed: 25247784.

35. Gu WJ, Wang F, Bakker J, et al. The effect of goal-directed therapy on mortality in patients with sepsis - earlier is better: a meta-analysis of randomized controlled trials. Crit Care. 2014; 18(5): 570, doi: 10.1186/ s13054-014-0570-5, indexed in Pubmed: 25327977.

36. Dellinger RP, Levy MM, Rhodes A, et al. Surviving sepsis campaign guidelines committee including the pediatric subgroup. Surviving sepsis campaign: international guidelines for management of severe sepsis and septic shock, 2012. Intensive Care Med. 2013; 39(2): 165-228, doi: 10.1007/s00134-012-2769-8, indexed in Pubmed: 23361625.

37. Osman D, Ridel C, Ray P, et al. Cardiac filling pressures are not appropriate to predict hemodynamic response to volume challenge. Crit Care Med. 2007; 35(1): 64-68, doi: 10.1097/01.CCM.0000249851.94101.4F, indexed in Pubmed: 17080001.

38. Chauvet JL, El-Dash S, Delastre O, et al. Early dynamic left intraventricular obstruction is associated with hypovolemia and high mortality in septic shock patients. Crit Care. 2015; 19: 262, doi: 10.1186/s13054015-0980-z, indexed in Pubmed: 26082197.

39. Morelli A, Ertmer C, Westphal M, et al. Effect of heart rate control with esmolol on hemodynamic and clinical outcomes in patients with septic shock: a randomized clinical trial. JAMA. 2013; 310(16): 1683-1691, doi: 10.1001/jama.2013.278477, indexed in Pubmed: 24108526.

40. Asfar P, Meziani F, Hamel JF, et al. SEPSISPAM Investigators. High versus low blood-pressure target in patients with septic shock. N Engl J Med. 2014; 370(17): 1583-1593, doi: 10.1056/NEJMoa1312173, indexed in Pubmed: 24635770 .

41. Hamzaoui O, Georger JF, Monnet X, et al. Early administration of norepinephrine increases cardiac preload and cardiac output in septic patients with life-threatening hypotension. Crit Care. 2010; 14(4): R142, doi: 10.1186/cc9207, indexed in Pubmed: 20670424.

42. Kipnis E, Vallet B. Early norepinephrine resuscitation of life-threatening hypotensive septic shock: it can do the job, but at what cost? Crit Care. 2010; 14(6): 450, doi: 10.1186/cc9299, indexed in Pubmed: 21067525.

43. Reardon DP, DeGrado JR, Anger KE, et al. Early vasopressin reduces incidence of new onset arrhythmias. J Crit Care. 2014; 29(4): 482-485, doi: 10.1016/j.jcrc.2014.03.005, indexed in Pubmed: 24747036.

44. Rosenberg MA, Manning WJ. Diastolic dysfunction and risk of atrial fibrillation: a mechanistic appraisal. Circulation. 2012; 126(19): 2353-2362, doi: 10.1161/CIRCULATIONAHA.112.113233, indexed in Pubmed: 23129702.
45. Jardin F, Vieillard-Baron A. Is there a safe plateau pressure in ARDS? The right heart only knows. Intensive Care Med. 2007; 33(3): 444-447, doi: 10.1007/s00134-007-0552-z, indexed in Pubmed: 17268795.

46. Nielsen J, Østergaard M, Kjaergaard J, et al. Lung recruitment maneuver depresses central hemodynamics in patients following cardiac surgery. Intensive Care Med. 2005; 31(9): 1189-1194, doi: 10.1007/s00134-0052732-z, indexed in Pubmed: 16096751.

47. Gernoth C, Wagner G, Pelosi P, et al. Respiratory and haemodynamic changes during decremental open lung positive end-expiratory pressure titration in patients with acute respiratory distress syndrome. Crit Care. 2009; 13(2): R59, doi: 10.1186/cc7786, indexed in Pubmed: 19374751.

48. Vieillard-Baron A, Charron C, Caille V, et al. Prone positioning unloads the right ventricle in severe ARDS. Chest. 2007; 132(5): 1440-1446, doi: 10.1378/chest.07-1013, indexed in Pubmed: 17925425.

49. Owens RC, Nolin TD. Antimicrobial-associated QT interval prolongation: pointes of interest. Clin Infect Dis. 2006; 43(12): 1603-1611, doi: 10.1086/508873, indexed in Pubmed: 17109296.

50. Simkó J, Csilek A, Karászi J, et al. Proarrhythmic potential of antimicrobial agents. Infection. 2008; 36(3): 194-206, doi: 10.1007/s15010-007-72118, indexed in Pubmed: 18454341.

51. Lorberbaum T, Sampson KJ, Chang JB, et al. Coupling data mining and laboratory experiments to discover drug interactions causing QT prolongation. J Am Coll Cardiol. 2016; 68(16): 1756-1764, doi: 10.1016/j. jacc.2016.07.761, indexed in Pubmed: 27737742.

52. Chinello P, Petrosillo N. QT interval prolongation and antiretroviral treatment: another point of interest. Clin Infect Dis. 2007; 44(10): 1388-9; author reply 1389, doi: 10.1086/516614, indexed in Pubmed: 17443482

53. Lopez JA, Harold JG, Rosenthal MC, et al. QT prolongation and torsades de pointes after administration of trimethoprim-sulfamethoxazole. Am J Cardiol. 1987; 59(4): 376-377, indexed in Pubmed: 3492908.

54. Berni E, de Voogd H, Halcox JP, et al. Risk of cardiovascular events, arrhythmia and all-cause mortality associated with clarithromycin versus alternative antibiotics prescribed for respiratory tract infections: a retrospective cohort study. BMJ Open. 2017; 7(1): e013398, doi: 10.1136/ bmjopen-2016-013398, indexed in Pubmed: 28115334.

55. Trifirò $G$, de Ridder $M$, Sultana J, et al. Use of azithromycin and risk of ventricular arrhythmia. CMAJ. 2017; 189(15): E560-E568, doi: 10.1503/ cmaj.160355, indexed in Pubmed: 28420680.

56. Wong AYS, Chan EW, Anand S, et al. Managing cardiovascular risk of macrolides: systematic review and meta-analysis. Drug Saf. 2017; 40(8): 663-677, doi: 10.1007/s40264-017-0533-2, indexed in Pubmed: 28397186.

57. Martin RIR, Pogoryelova O, Koref MS, et al. Atrial fibrillation associated with ivabradine treatment: meta-analysis of randomised controlled trials. Heart. 2014; 100(19): 1506-1510, doi: 10.1136/heartjnl-2014-305482, indexed in Pubmed: 24951486.

58. Vitale D, De Santis V, Guarracino F, et al. Use of ivabradine in catecholamine-induced tachycardia after high-risk cardiac surgery. Clin Res Cardiol. 2010; 99(12): 853-855, doi: 10.1007/s00392-010-0208-9, indexed in Pubmed: 20821020.

59. De Santis V, Frati G, Greco E, et al. Ivabradine: a preliminary observation for a new terapeutic role in patients with multiple organ dysfunction syndrome. Clin Res Cardiol. 2014; 103(10): 831-834, doi: 10.1007/ s00392-014-0722-2, indexed in Pubmed: 24805930.

60. Bugg NC, Jones JA. Hypophosphataemia. Pathophysiology, effects and management on the intensive care unit. Anaesthesia. 1998; 53(9): 895-902, indexed in Pubmed: 9849285.

61. Schwartz A, Brotfain E, Koyfman L, et al. Association between hypophosphatemia and cardiac arrhythmias in the early stage of sepsis: could phosphorus replacement treatment reduce the incidence of arrhythmias? Electrolyte Blood Press. 2014; 12(1): 19-25, doi: 10.5049/ EBP.2014.12.1.19, indexed in Pubmed: 25061469.

62. Velissaris D, Karamouzos V, Pierrakos C, et al. Hypomagnesemia in critically III sepsis patients. J Clin Med Res. 2015; 7(12): 911-918, doi: 10.14740/jocmr2351w, indexed in Pubmed: 26566403.

63. Panahi Y, Mojtahedzadeh M, Najafi A, et al. The role of magnesium sulfate in the intensive care unit. EXCLI J. 2017; 16: 464-482, doi: 10.17179/ excli2017-182, indexed in Pubmed: 28694751.

64. Lee JW. Fluid and electrolyte disturbances in critically ill patients. Electrolyte Blood Press. 2010; 8(2): 72-81, doi: 10.5049/EBP.2010.8.2.72, indexed in Pubmed: 21468200.

65. Zivin JR, Gooley T, Zager RA, et al. Hypocalcemia: a pervasive metabolic abnormality in the critically ill. Am J Kidney Dis. 2001; 37(4): 689-698, indexed in Pubmed: 11273867. 
66. Gamst J, Christiansen CF, Rasmussen BS, et al. Pre-existing atrial fibrillation and risk of arterial thromboembolism and death in intensive care unit patients: a population-based cohort study. Crit Care. 2015; 19: 299, doi: 10.1186/s13054-015-1007-5, indexed in Pubmed: 26286550.

67. Sugioka K, Takagi M, Sakamoto $S$, et al. Predictors of silent brain infarction on magnetic resonance imaging in patients with nonvalvular atrial fibrillation: A transesophageal echocardiographic study. Am Heart J. 2015; 169(6): 783-790, doi: 10.1016/j.ahj.2015.03.016, indexed in Pubmed: 26027615.

68. Kirchhof $\mathrm{P}, \mathrm{Ammentorp} \mathrm{B}$, Darius $\mathrm{H}$, et al. Management of atrial fibrillation in seven European countries after the publication of the 2010 ESC Guidelines on atrial fibrillation: primary results of the PREvention of thromboemolic events - European Registry in Atrial Fibrillation (PREFER in AF). Europace. 2014; 16(1): 6-14, doi: 10.1093/europace/ eut263, indexed in Pubmed: 24084680.

69. Arrigo $M$, Jaeger N, Seifert B, et al. Disappointing success of electrical cardioversion for new-onset atrial fibrillation in cardiosurgical ICU patients. Crit Care Med. 2015; 43(11): 2354-2359, doi: 10.1097/ CCM.0000000000001257, indexed in Pubmed: 26468695.

70. Arrigo M, Jaeger N, Seifert B, et al. Disappointing success of electrical cardioversion for new-onset atrial fibrillation in cardiosurgical ICU patients. Crit Care Med. 2015; 43(11): 2354-2359, doi: 10.1097/ CCM.0000000000001257, indexed in Pubmed: 26468695.

71. Hughes M, Binning A. Intravenous amiodarone in intensive care. Time for a reappraisal? Intensive Care Med. 2000; 26(12): 1730-1739, indexed in Pubmed: 11271079.

72. Papiris SA, Triantafillidou C, Kolilekas L, et al. Amiodarone: review of pulmonary effects and toxicity. Drug Saf. 2010; 33(7): 539-558, doi: 10.2165/11532320-000000000-00000, indexed in Pubmed: 20553056.

73. Ganetsky MBE. Antiarythmic agents. In: Irwin RS. ed. Intensive care medicine. 6th ed. Wolters Kluwer/Liincott, Williams\&Wilkins, Philadelhia 2008.

74. Hassan S, Ayoub W, Hassan M, et al. Amiodarone-induced myxoedema coma. BMJ Case Rep. 2014; 2014, doi: 10.1136/bcr-2013-202338, indexed in Pubmed: 24729111

75. Hofmann A, Nawara C, Ofluoglu S, et al. Incidence and predictability of amiodarone-induced thyrotoxicosis and hypothyroidism. Wien Klin Wochenschr. 2008; 120(15-16): 493-498, doi: 10.1007/s00508-0081017-2, indexed in Pubmed: 18820854.

76. Jaiswal P, Attar BM, Yap JE, et al. Acute liver failure with amiodarone infusion: A case report and systematic review. J Clin Pharm Ther. 2017 [Epub ahead of print], doi: 10.1111/jcpt.12594, indexed in Pubmed: 28714083.

77. Bravo A, Drewe J, Schlienger $R$, et al. Hepatotoxicity during rapid intravenous loading with amiodarone: Description of three cases and review of the literature*. Critical Care Medicine. 2005; 33(1): 128-134, doi: 10.1097/01.ccm.0000151048.72393.44.

78. Charles PE, Doise JM, Quenot JP, et al. Amiodarone-related acute respiratory distress syndrome following sudden withdrawal of steroids. Respiration. 2006; 73(2): 248-249, doi: 10.1159/000088010, indexed in Pubmed: 16131795.

79. Singh VK, Maheshwari V. Acute respiratory distress syndrome complicated by amiodarone induced pulmonary fibrosis: don't let your guard down. J Clin Diagn Res. 2017; 11(4): UD01-UD02, doi: 10.7860/ JCDR/2017/24710.9674, indexed in Pubmed: 28571241.

80. Echt DS, Liebson PR, Mitchell LB, et al. Mortality and morbidity in patients receiving encainide, flecainide, or placebo. The Cardiac Arrhythmia Suppression Trial. N Engl J Med. 1991; 324(12): 781-788, doi: 10.1056/NEJM199103213241201, indexed in Pubmed: 1900101.

81. Chevalier $P$, Durand-Dubief $A, B$ Buri $H$, et al. Amiodarone versus placebo and class Ic drugs for cardioversion of recent-onset atrial fibrillation: a meta-analysis. J Am Coll Cardiol. 2003; 41(2): 255-262, indexed in Pubmed: 12535819.

82. Courand PYNd, Sibellas F, Ranc $S$, et al. Arrhythmogenic effect of flecainide toxicity. Cardiol J. 2013; 20(2): 203-205, doi: 10.5603/CJ.2013.0035, indexed in Pubmed: 23558880.

83. Aliot E, Capucci A, Crijns HJ, et al. Twenty-five years in the making: flecainide is safe and effective for the management of atrial fibrillation. Europace. 2011; 13(2): 161-173, doi: 10.1093/europace/euq382, indexed in Pubmed: 21138930.

84. Varon J, Marik PE. Irwin and Rie's intensive care medicine. In: Irwin RS, Rippe JM. ed. 6th ed. . Wolters Kluwer Health/Liincott Williams \& Wilkins, Philadelhia 2008.

85. Rudiger A. Beta-block the septic heart. Crit Care Med. 2010; 38(10 Suppl): S608-S612, doi: 10.1097/CCM.0b013e3181f204ca, indexed in Pubmed: 21164404.
86. Morelli A, Donati A, Ertmer C, et al. Microvascular effects of heart rate control with esmolol in patients with septic shock: a pilot study. Crit Care Med. 2013; 41(9): 2162-2168, doi: 10.1097/CCM.0b013e31828a678d, indexed in Pubmed: 23873274.

87. Morelli A, Ertmer C, Westphal M, et al. Effect of heart rate control with esmolol on hemodynamic and clinical outcomes in patients with septic shock: a randomized clinical trial. JAMA. 2013;310(16): 1683-1691, doi: 10.1001/jama.2013.278477, indexed in Pubmed: 24108526.

88. Balik M, Rulisek J, Leden P, et al. Concomitant use of beta- 1 adrenoreceptor blocker and norepinephrine in patients with septic shock. Wien Klin Wochenschr. 2012; 124(15-16): 552-556, doi: 10.1007/s00508-0120209-y, indexed in Pubmed: 22815003.

89. Balik M, Rulisek J, Leden P, et al. Concomitant use of beta-1 adrenoreceptor blocker and norepinephrine in patients with septic shock. Reply to a letter to the authors. Wien Klin Wochenschr. 2014; 126(7-8): 246-247, doi: 10.1007/s00508-013-0487-z, indexed in Pubmed: 24343046.

90. McLean AS, Taccone FS, Vieillard-Baron A. Beta-blockers in septic shock to optimize hemodynamics? No. Intensive Care Med. 2016;42(10): 1610 1612, doi: 10.1007/s00134-016-4407-3, indexed in Pubmed: 27349242.

91. Vieillard-Baron A, Caille V, Charron C, et al. Actual incidence of global left ventricular hypokinesia in adult septic shock. Crit Care Med. 2008; 36(6): 1701-1706, doi: 10.1097/CCM.0b013e318174db05, indexed in Pubmed: 18496368.

92. Aboab J, Sebille V, Jourdain M, et al. Effects of esmolol on systemic and pulmonary hemodynamics and on oxygenation in pigs with hypodynamic endotoxin shock. Intensive Care Med. 2011; 37(8): 1344-1351, doi: 10.1007/s00134-011-2236-y, indexed in Pubmed: 21567116.

93. Ackland GL, Yao ST, Rudiger A, et al. Cardioprotection, attenuated systemic inflammation, and survival benefit of beta1-adrenoceptor blockade in severe sepsis in rats. Crit Care Med. 2010; 38(2): 388-394, doi: 10.1097/CCM.0b013e3181c03dfa, indexed in Pubmed: 19829100.

94. Hagiwara $\mathrm{S}$, Iwasaka $\mathrm{H}, \mathrm{Maeda} \mathrm{H}$, et al. Landiolol, an ultrashort-acting beta1-adrenoceptor antagonist, has protective effects in an LPS-induced systemic inflammation model. Shock. 2009; 31(5): 515-520, doi: 10.1097/SHK.0b013e3181863689, indexed in Pubmed: 18791493.

95. Suzuki T, Morisaki H, Serita R, et al. Infusion of the beta-adrenergic blocker esmolol attenuates myocardial dysfunction in septic rats. Crit Care Med. 2005; 33(10): 2294-2301, indexed in Pubmed: 16215384.

96. Poldermans D, Boersma E, Bax JJ, et al. The effect of bisoprolol on perioperative mortality and myocardial infarction in high-risk patients undergoing vascular surgery. Dutch Echocardiographic Cardiac Risk Evaluation Applying Stress Echocardiography Study Group. N Engl J Med. 1999; 341(24): 1789-1794, doi: 10.1056/NEJM199912093412402, indexed in Pubmed: 10588963.

97. Balik M, Rulisek J, Leden $\mathrm{P}$, et al. Concomitant use of beta-1 adrenoreceptor blocker and norepinephrine in patients with septic shock. Wien Klin Wochenschr. 2012; 124(15-16):552-556, doi: 10.1007/s00508-0120209-y, indexed in Pubmed: 22815003.

98. Balik M, Rulisek J, Leden P, et al. Concomitant use of beta-1 adrenoreceptor blocker and norepinephrine in patients with septic shock. Reply to a letter to the authors. Wien Klin Wochenschr. 2014; 126(7-8): 246-247, doi: 10.1007/s00508-013-0487-z, indexed in Pubmed: 24343046.

99. Ojima T, Nakamori M, Nakamura M, et al. Randomized clinical trial of landiolol hydrochloride for the prevention of atrial fibrillation and postoperative complications after oesophagectomy for cancer. $\mathrm{Br}$ J Surg. 2017; 104(8): 1003-1009, doi: 10.1002/bjs.10548, indexed in Pubmed: 28444964.

100. Nojiri T, Yamamoto K, Maeda H, et al. Efficacy of low-dose landiolol, an ultrashort-acting $\beta$-blocker, on postoperative atrial fibrillation in patients undergoing pulmonary resection for lung cancer. Gen Thorac Cardiovasc Surg. 2011; 59(12): 799-805, doi: 10.1007/s11748-011-0841$x$, indexed in Pubmed: 22173677.

101. Nakano T, Shimizu K, Kawashima O, et al. Effect of landiolol hydrochloride, an ultra-short-acting beta 1-selective blocker, on supraventricular tachycardia, atrial fibrillation and flutter after pulmonary resection. J Clin Pharm Ther. 2012; 37(4): 431-435, doi: 10.1111/j.1365-2710.2011.01315.x, indexed in Pubmed: 22059486.

102. Yamakage M, Iwasaki S, Jeong SW, et al. Beta-1 selective adrenergic antagonist landiolol and esmolol can be safely used in patients with airway hyperreactivity. Heart Lung. 2009; 38(1): 48-55, doi: 10.1016/j. hrtlng.2008.01.002, indexed in Pubmed: 19150530.

103. Yang EH, Shah S, Criley JM. Digitalis toxicity: a fading but crucial complication to recognize. Am J Med. 2012; 125(4): 337-343, doi: 10.1016/j. amjmed.2011.09.019, indexed in Pubmed: 22444097. 
104. QureshiW, O'Neal WT, Soliman EZ, et al. Systematic review and meta-analysis of mortality and digoxin use in atrial fibrillation. Cardiol J.2016; 23(3): 333-343, doi: 10.5603/CJ.a2016.0016, indexed in Pubmed: 27064796.

105. Vamos M, Erath JW, Hohnloser SH. Digoxin-associated mortality: a systematic review and meta-analysis of the literature. Eur Heart J. 2015; 36(28): 1831-1838, doi: 10.1093/eurheartj/ehv143, indexed in Pubmed: 25939649.

106. Walkey AJ, Evans SR, Winter MR, et al. Practice patterns and outcomes of treatments for atrial fibrillation during sepsis: a propensity-matched cohort study. Chest. 2016; 149(1): 74-83, doi: 10.1378/chest.15-0959, indexed in Pubmed: 26270396.

107. Ziff OJ, Lane DA, Samra M, et al. Safety and efficacy of digoxin: systematic review and meta-analysis of observational and controlled trial data. BMJ. 2015; 351: h4451, indexed in Pubmed: 26321114.

108. Sibley S, Muscedere J. New-onset atrial fibrillation in critically ill patients. Can Respir J. 2015; 22(3): 179-182, indexed in Pubmed: 26057373.

109. Levy MM, Fink MP, Marshall JC, et al. SCCM/ESICM/ACCP/ATS/SIS, International Sepsis Definitions Conference. 2001 SCCM/ESICM/ACCP/ATS/SIS International Sepsis Definitions Conference. Intensive Care Med. 2003;29(4): 530-538, doi: 10.1007/s00134-003-1662-x, indexed in Pubmed: 12664219.

110. Singer $M$, Deutschman CS, Seymour CW, et al. The third international consensus definitions for sepsis and septic shock (Sepsis-3). JAMA. 2016;315(8): 801-810, doi: 10.1001/jama.2016.0287, indexed in Pubmed: 26903338.

111. Sterling SA, Puskarich MA, Glass AF, et al. The impact of the sepsis-3 septic shock definition on previously defined septic shock patients. Crit Care Med. 2017; 45(9): 1436-1442, doi: 10.1097/ CCM.0000000000002512, indexed in Pubmed: 28542029.

112. Jensen $M B$, Sloth $E$, Larsen $K M$, et al. Transthoracic echocardiography for cardiopulmonary monitoring in intensive care. Eur J Anaesthesiol. 2004; 21(9): 700-707, indexed in Pubmed: 15595582.

113. Suman-Horduna I, Roy D, Frasure-Smith N, et al. AF-CHF Trial Investigators, AF-CHF investigators, Atrial Fibrillation and Congestive Heart Failure Investigators, Atrial Fibrillation and Congestive Heart Failure Investigators. Rhythm control versus rate control for atrial fibrillation and heart failure. N Engl J Med. 2008; 358(25): 2667-2677, doi: 10.1056/ NEJMoa0708789, indexed in Pubmed: 18565859.
114. Van Gelder IC, Hagens VE, Bosker HA, et al. Rate control versus electrical cardioversion for persistent atrial fibrillation study group. A comparison of rate control and rhythm control in patients with recurrent persistent atrial fibrillation. N Engl J Med. 2002; 347(23): 1834-1840, doi: 10.1056/ NEJMoa021375, indexed in Pubmed: 12466507.

115. AFFIRM First Antiarrhythmic Drug Substudy Investigators. Maintenance of sinus rhythm in patients with atrial fibrillation: an AFFIRM substudy of the first antiarrhythmic drug. J Am Coll Cardiol. 2003; 42(1): 20-29, indexed in Pubmed: 12849654.

116. Gillinov AM, Bagiella E, Moskowitz AJ, et al. CTSN. Rate control versus rhythm control for atrial fibrillation after cardiac surgery. N Engl J Med. 2016; 374(20): 1911-1921, doi: 10.1056/NEJMoa1602002, indexed in Pubmed: 27043047.

117. Marchese P, Bursi F, Delle Donne G, et al. Indexed left atrial volume predicts the recurrence of non-valvular atrial fibrillation after successful cardioversion. Eur J Echocardiogr. 2011; 12(3): 214-221, doi: 10.1093/ ejechocard/jeq176, indexed in Pubmed: 21149290.

118. Fornengo $C$, Antolini M, Frea $S$, et al. Prediction of atrial fibrillation recurrence after cardioversion in patients with left-atrial dilation. Eur Heart J Cardiovasc Imaging. 2015; 16(3): 335-341, doi: 10.1093/ehjci/ jeu193, indexed in Pubmed: 25274966.

\section{Corresponding author:}

Martin Balik M.D., Ph.D.

Department of Anaesthesiology and Intensive Care

$1^{\text {st }}$ Faculty of Medicine

Charles University and General University Hospital

U Nemocnice 2, Prague 2, 128 00, Czechia

e-mail:martin.balik@vfn.cz

Received: 15.09.2017

Accepted: 11.11.2017 